\title{
Mechatronic Analysis for Feeding a Structure of a Machine Tool Using Multi-body Dynamics
}

\author{
Jin Woo Choi*
}

(Manuscript received: Jul, 19, 2012 / Revised: Aug, 27, 2012 / Accepted: Aug, 30, 2012)

다물체 동역학을 활용한 공작기계 구조물 이송을 위한 메카트로닉 해석

최진우*

\begin{abstract}
In this study, a rigid multi-body dynamic model has been developed for mechatronic analysis to evaluate dynamic behavior of a machine tool. The development environment was the commercialized analysis tool, ADAMS, for rigid multi-body dynamic analysis. A simplified servo control logic was implemented in the tool using its functions in order to negate any external tool of control definition. The advantage of the internal implementation includes convenience of the analysis process by saving time and efforts. Application of this development to a machine tool helps to evaluate its dynamic behavior against feeding its component, to calculate the motor torque, and to optimize parameters of the control logic.
\end{abstract}

Key Words : Rigid multi-body dynamic model(강체 다물체 동역학 모델), Mechatronic analysis(메카트로닉 해석), Feeding(이송), Servo control logic(서보 제어 로직), Internal implementation(내부 구현)

\section{Introduction}

A CNC (computer numerical control) machine tool is a representative mechatronic system as it has mechanical elements such as structures, ball screws and electronic elements including motors and servo logic. A motor as an actuator rotates a ball screw which converts the rotation into a translation force. The translation force feeds a structure such as a table to the position required. The feeding is controlled with the servo control logic composed of, for example, gains and integral terms. The mechatronic characteristics including the gains and the spring constant of the ball screw need to be evaluated to determine the feeding performance of the $\mathrm{CNC}$ machine tool.

Productivity depends on feeding performance of a machine tool. High velocity feeding locates a structure, say, the table of the machine tool, in a short time. The rapid feeding can be obtained from high acceleration and jerk ${ }^{(1,2)}$ leading to the great feeding force obtainable from a high motor torque. The feeding force can compress the ball screw and, therefore, affect the time of the structure location. It is necessary to evaluate the feeding performance of a machine tool including the maximum acceleration.

An analysis needs to be carried out to evaluate mechatronic performance of a machine tool. The mechatronic analysis can be used to determine the properties of mechanical components, 
such as stiffness of a bearing, leading to the feeding velocity required. On the contrary, it can identify the optimal gains of the control logic implemented in a CNC.

Research has been conducted on mechatronic analysis. Theoretical dynamic models were developed for the analysis ${ }^{(3-5)}$. They are constructed with springs and masses. Once a dynamic model is constructed and connected with the logic, it can identify the mechatronic characteristics in a short time. However, it is difficult for the theoretical model to evaluate an eccentric mass, which may damage shoes of guide rails. The approaches using finite element analysis (FEA) ${ }^{(1)}$ have the advantage to identify the influence of the stiffness of a structure, say, column, on the mechatronic performance. However, they tend to need a great deal of computation time.

In this study, rigid multi-body dynamic (RMBD) model has been developed for mechatronic analysis in the environment of the commercial tool, ADAMS (Automatic Dynamic Analysis of Mechanical Systems). The control logic is implemented with its built-in functions whereas an external tool such as MATLAB is used for generation of the control logic leading to an extra cost. The mechatonic analysis can evaluate the dynamic characteristics of motion in a minimum time. It can reflect the location of the center of gravity (COG) of a moving part whereas it is difficult for theoretical models to consider the COG.

A portal-type machine tool is used as an example for RMBD mechatronic analysis. The stiffness of feeding components such as a ball screw is obtained and implemented using an analysis element such as spring element. The RMBD mechatronic analysis evaluates the influence of a semi-closed loop control using the control logic on motion in comparison with an

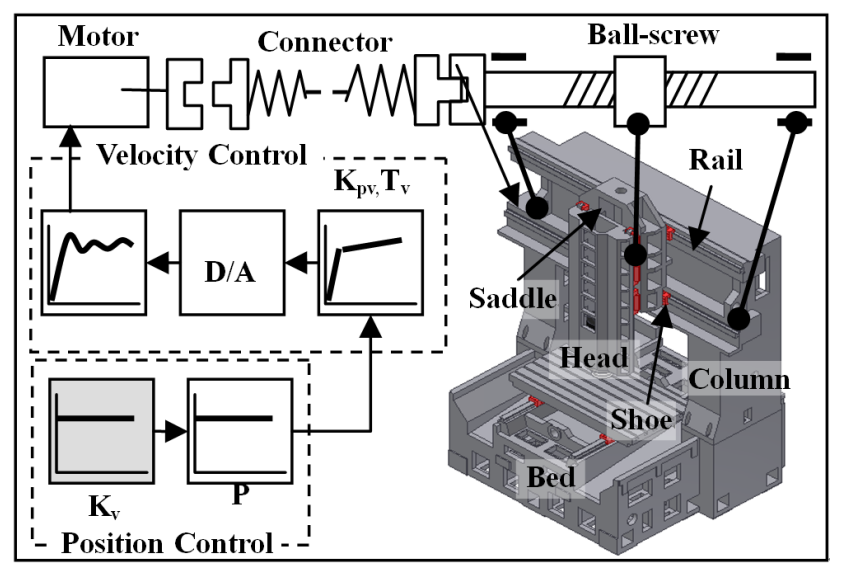

Fig. 1 Ball-screw feed system open loop control using no control logic ${ }^{(1)}$.

\section{Feeding in a closed loop control}

Fig. 1 shows a feeding mechanism with a semi-closed loop control for the mechatronic system of a machine tool. The linear motion (LM) shoes are connected with the saddle and move along with their mating rails carrying the saddle. The ball-screw converts the rotation of the motor torque into the translation of the saddle. The motor is controlled by the velocity loop and position loop embedded in a computer numerical control (CNC) and subsequently, positions the saddle according to set-points. The set-points define desirable positions of a structure with respect to time. In consequence, the CNC controls the velocity and position of the saddle according to the control logic.

If the CNC determines the saddle to be located behind its desired set-point, it speeds up the structure by increasing the rotational speed of the motor, subsequently, the rotational speed of the ball screw, and finally the speed of the structure due to its connection with the screw. The variation in the velocity of the structure causes acceleration and, therefore, the force corresponding to the acceleration and the mass of the structure. The force may cause deformation of the structure and others and damage bearing components such as LM shoes or nuts of the ball-screws. These motion parameters, velocity and acceleration, in the control loop need to be evaluated with dynamic analysis.

A simplified servo control logic ${ }^{(6,7)}$ shown in Fig. 2 is used for mechatronic analysis in this study. A servo control logic is commonly composed of position control, velocity control, and current control of a motor and occasionally uses feedforward control method for an improvement in, for example, cutting surface roughness.

The simplified logic in Fig. 2 has only proportional position

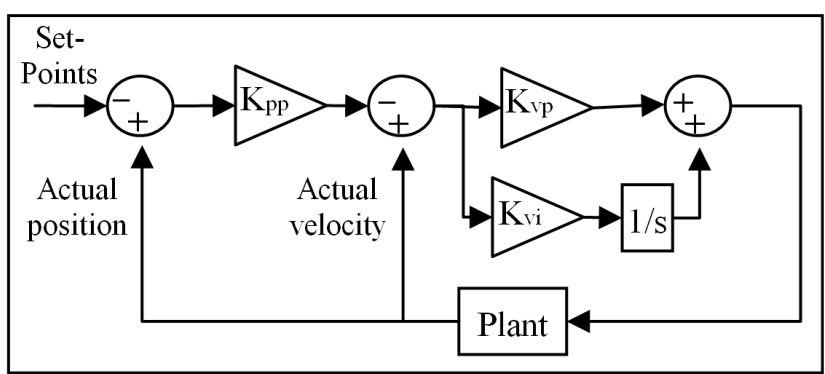

Fig. 2 Simplified servo control 
controller and proportional-integral velocity controller as the current loop usually contains a very small gain considering position and velocity controls and therefore, it can be neglected $^{(7)}$. ' $K_{\mathrm{pp}}$ ', $\mathrm{K}_{\mathrm{vp}}$ ', and ' $\mathrm{K}_{\mathrm{vi}}$ ' are gains for the controllers. The plant in Fig. 2 is the mechanical system of a machine tool.

This simplified logic can be used for conceptual design of a machine tool as the structures of the machine tool are not fully defined unlike detail design. At the detail design stage, an accurate result is required with full definition of structures but, at the conceptual design stage, approximate definition of structures is required in order to produce results at a relatively low accuracy. Accordingly, the simplified control logic can be used for mechatronic analysis for a machine tool at the conceptual design stage. This control logic is implemented in the RMBD analysis.

\section{Modeling for rigid dynamic analysis}

In this study, RMBD mechatronic analysis is used for evaluation of a machine tool. Rigid body analysis takes a minimum time for computation whereas FEA takes a lot of computation time. Rigid body analysis enables diverse design candidates to be evaluated and compared with each other in a minimum time and, therefore, it can be used for an early design stage where a trade-off study is needed in order to

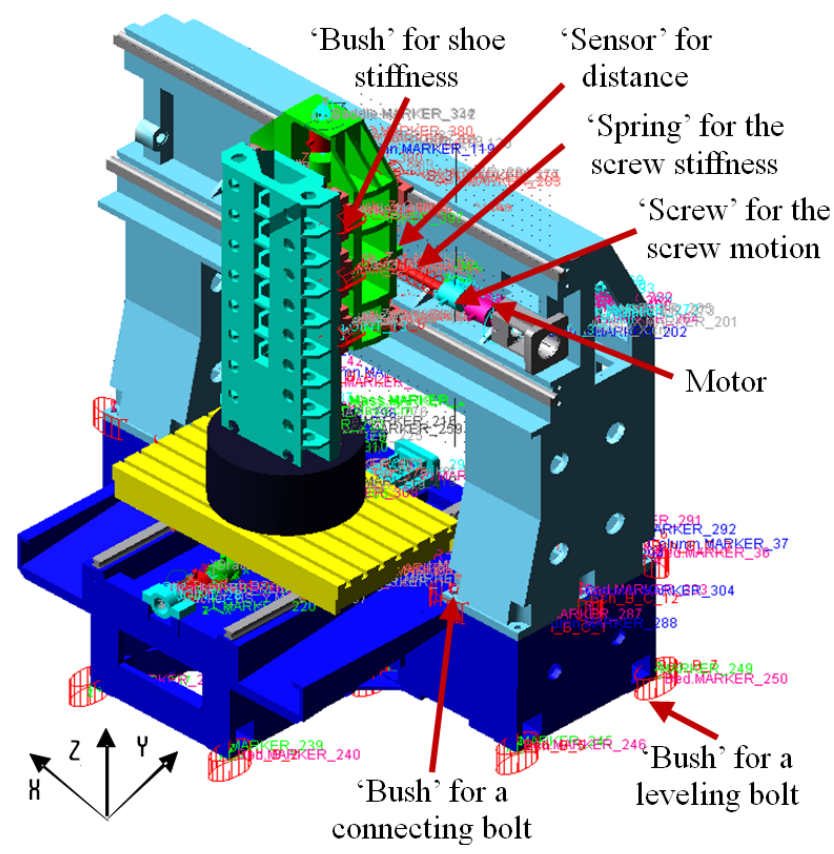

Fig. 3 Rigid dynamic analysis modeling identify a desirable design among design candidates.

Fig. 3 shows a machine tool and its analytical model for the mechatronic analysis and Table 4 presents the properties required to run the analysis. Casting iron is used for the major structures. It is a portal type machining center composed of the five major casting-iron structures, bed, column, saddle, head, and table. It has the three feeding axes of saddle movement in $\mathrm{X}$ axis, table movement in $\mathrm{Y}$ axis, and head movement in $\mathrm{Z}$ axis. The size of the machine tool is 2485 $\mathrm{mm}$ in height, $1690 \mathrm{~mm}$ in length, and $2220 \mathrm{~mm}$ in width.

The analysis tool, $\mathrm{ADAMS}^{(9)}$, is used for evaluation of dynamic characteristics of the machine tool in this study. Analytical elements such as 'Joint', 'Spring', and 'Screw' are used to implement the motions and the mechanical elements such as the ball screw and bolts. 'Joint' is used to define a relative motion of a part to its mating part. It includes translational joint, rotational joint, spherical joint, slot joint, and screw joint. 'Screw' is used to define translation with respect to rotation. 'Spring' allows for definition of the onedirectional stiffness and damping between two parts.

Spring and screw elements are used for the stiffness and the motion of the ball screw, respectively, in each axis. The stiffness is calculated with the elastic modulus of the material, structural steel, the diameter, and the length of the ball screw. Bush elements are used for connecting bolts and leveling bolts. The stiffness of the connecting bolt can be calculated with the pressure area ${ }^{(10)}$ as shown in Fig. 4 and implemented in the 'Bush' element.

Translational joint is used to connect a shoe with its

Table 1 Properties for the machine tool

\begin{tabular}{|c|c|c|c|}
\hline Type & Item & Property & Value \\
\hline \multirow{4}{*}{ Material } & \multirow{4}{*}{$\begin{array}{l}\text { Casting } \\
\text { Iron }\end{array}$} & Young Modulus & $125 \mathrm{GPa}$ \\
\hline & & Poisson's ratio & 0.28 \\
\hline & & Damping & 0.0015 \\
\hline & & Density & $7250 \mathrm{~kg} / \mathrm{m}^{3}$ \\
\hline \multirow{6}{*}{$\begin{array}{l}\text { Design } \\
\text { details }\end{array}$} & \multirow{2}{*}{ Ball screw } & Size & M36 \\
\hline & & Pitch & $13 \mathrm{~mm}$ \\
\hline & \multirow{2}{*}{$\begin{array}{c}\text { Leveling } \\
\text { bolt }\end{array}$} & Size & M24 \\
\hline & & Stiffness ${ }^{(8)}$ & $16 \mathrm{kN} / \mathrm{mm}$ \\
\hline & \multirow{2}{*}{ Extra mass } & Motor $(\mathrm{X}, \mathrm{Y}, \mathrm{Z})$ & $30 \mathrm{~kg}$ \\
\hline & & Spindle & $50 \mathrm{~kg}$ \\
\hline \multirow{2}{*}{ Motion } & \multirow{2}{*}{ Feeding } & Time duration & $0.04 \mathrm{~s}$ \\
\hline & & Distance & $1 \mathrm{~mm}$ \\
\hline
\end{tabular}


mating rail and rotational joint is to connect the motor with its bracket as shown in Fig. 3. Rotation is applied to the motor, the motor rotates the screw element, and then the screw feeds the saddle with the spring connection.

Internal functions of the analysis tool, ADAMS, are used to define control loop and its parameters. The 'STEP' function, for example, 'step (time, 0.01, 0, 0.05, 27.7d)', generates the set points as shown in Fig. 5. It is applied to the rotational joint of the motor and leads to $1 \mathrm{~mm}$ for the time duration of $0.04 \mathrm{sec}(=0.05-0.01)$ with the rotation angle of 27.7 degrees and the pitch of $13 \mathrm{~mm}$. 'DIF' function is used to

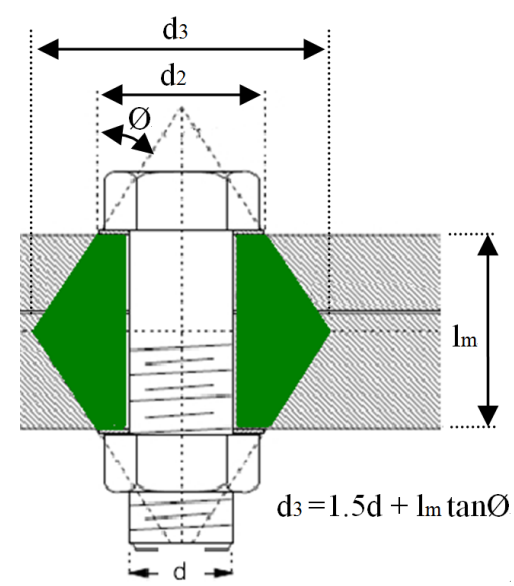

Fig. 4 Bolt-frusta model for fastening stiffness ${ }^{(10)}$

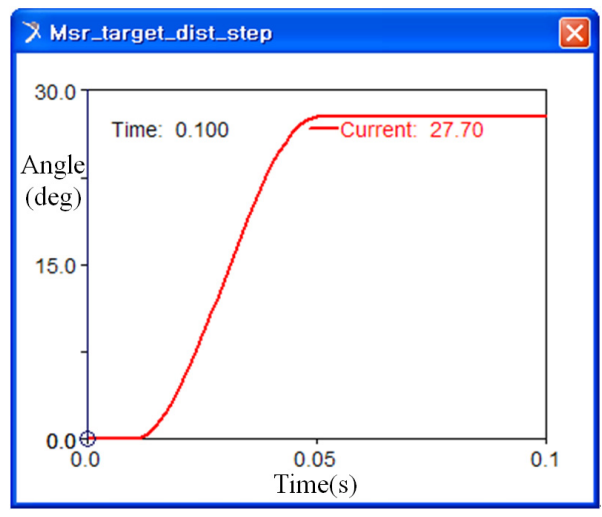

Fig. 5 STEP function for set-points

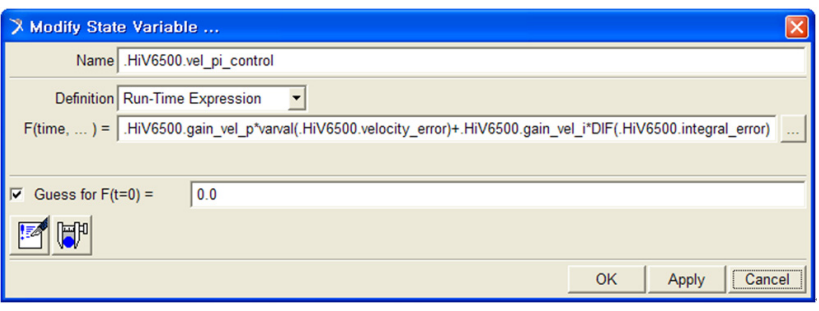

Fig. 6 Definition of a variable in ADAMS defines ' $1 / \mathrm{s}$ ' in Fig. 2 with 'Differential Equation' for integration as shown in Fig. 6.

This internal definition facilitates connection of the control and the plant for RMBD mechatronic analysis whereas an external definition ${ }^{(11,12)}$ using a commercialized control tool such as 'MATLAB SIMULINK' necessitates export of the plant constructed in the analysis and connection with the control tool. The post-processing of the analysis is performed in the analysis tool requiring import of the analysis result from the control tool. If a control loop can be easily implemented, it is recommended to define it in the analysis tool without extra cost of the commercial control tool and time for export and import of analysis data.

\section{Rigid multi-body dynamic analysis}

In this study, the RMBD mechatronic analysis carried out for the machine tool took less than 30 seconds for one run whereas FEA takes dozens of hours ${ }^{(1)}$. As a result, it can be found that the mechatronic analysis allows for rapid evaluation of dynamic behavior of the structure fed and, in addition, the other structures due to their connection. It can be extended to evaluation of the influence of mass change of a structure on dynamic behavior of other structures. The evaluation is considered useful at the conceptual design stage to assess various design candidates.

Fig. 7 presents the set points and the location of the head end (considered as tool center point) with and without the control loop, respectively, in $\mathrm{X}$ axis. Even if the set-point is applied to the motor of the saddle, the point of interest is the tool center point (head end in this study) as the final target to be controlled. This is because the saddle is fed

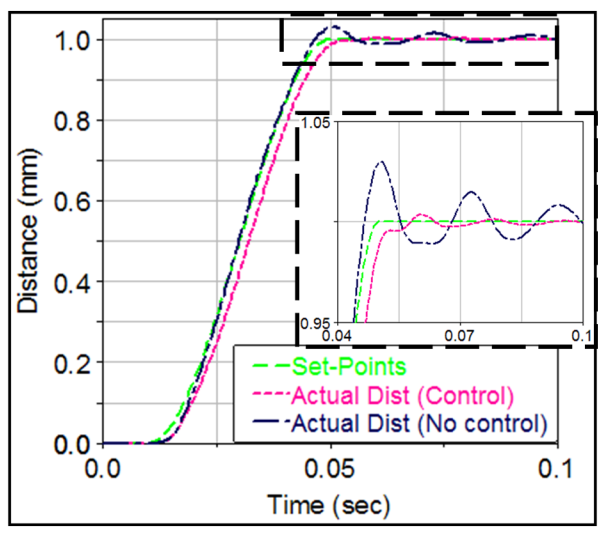

Fig. 7 Feeding distance of the head 
under control in order to locate the tool to the designated destination. The mean velocity of the feeding is $25 \mathrm{~mm} / \mathrm{sec}$ with the distance of $1 \mathrm{~mm}$ and the time duration of 0.04 second. This RMBD mechatronic analysis can evaluate a change in velocity with ease and in a minimum time.

The head end in no control, in Fig. 7, vibrates greater than the one in control as its overshooting is greater and, therefore, its convergence takes a longer time. The head end in control is retarded behind the set-points. Fig. 8 gives the movement of the table center point in $\mathrm{X}$ direction. The amplitude of the vibration is greater in no control than in control. This is because of the great dynamic behavior of the saddle.

Fig. 9 shows the reaction force from the saddle feeding at the time of 0.5 second. The direction and magnitude of the force varies according to the location of the saddle fed. The reaction force at the screw joint is useful to calculate the torque of the motor for the saddle.

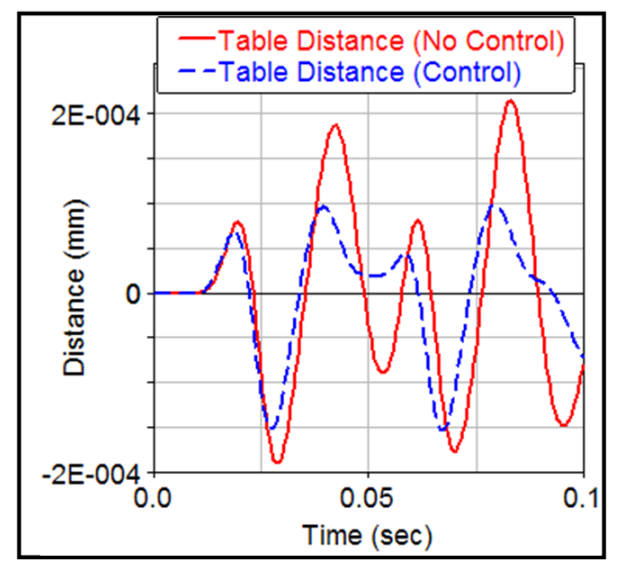

Fig. 8 Movement of the table

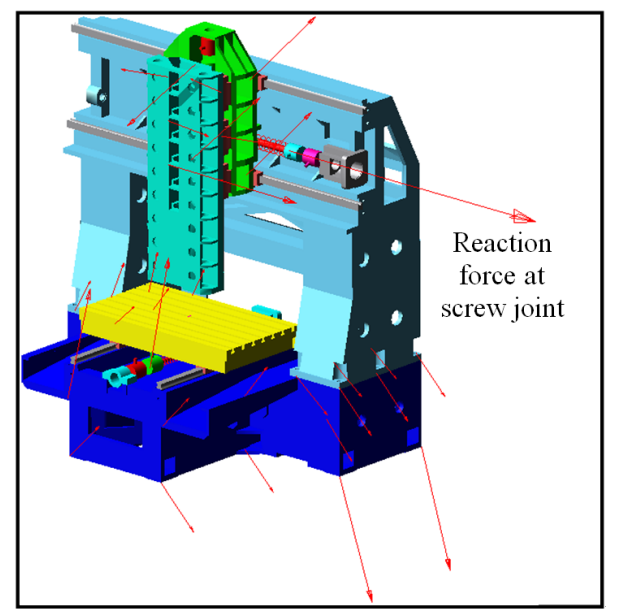

Fig. 9 Reaction force from the saddle feeding
The gains of $\mathrm{K}_{\mathrm{pp}}, \mathrm{K}_{\mathrm{vp}}$, and $\mathrm{K}_{\mathrm{vi}}$ were 1000, 3, and 5, respectively, for the mechatronic analysis in this study. These gains can be optimized in order to obtain a smooth dynamic behavior or to minimize the convergence time of feeding a structure. Multiple executions of the analysis or application of an optimization theory allows for the gain optimization.

\section{Conclusion}

In this paper, research has been carried out on development of a mechatronic model to evaluate dynamic behavior of a machine tool. The model was used for rigid multi-body mechatronic analysis in the environment of the commercialized analysis tool, ADAMS. The elements of the tool such as 'Spring', 'Bush', and 'Screw' are utilized to build up the analytical model.

The analytical model has the following characteristics;

(1) A simplified servo control logic was implemented in the tool in order not to use any external tool of control definition. The internal implementation facilitates the process of the mechatronic analysis with the control logic. As it is a semi-closed loop, the set-points were applied to the feeding motor of a structure, say, saddle in this research, but dynamic behavior of the tool center point and also its convergence were evaluated.

(2) Results from the analysis help to evaluate the dynamic behavior of a machine tool against feeding of a structure in semi-closed loop control. The size of the motor can be determined with the reaction force to the structure fed. This mechatronic analysis can optimize the control parameters, especially, gains against an objective of, say, convergence time.

(3) It is recommendable to apply this rigid mechatronic analysis to the conceptual design stage in that it takes a minimum time of computation, say, less than 30 seconds for the example in this study. The analysis enables diverse design candidates to be evaluated in a short time and the best design to be identified with their trade-off study.

This study needs to be extended to detail servo control logic inclusive of motor control loop. The simplified logic negated the motor control with a small gain in this study. An accurate mechatronic analysis could be carried out with a precisely defined control including the motor control. 


\section{References}

(1) Choi, J. W., and Lee, T. H., 2010, "Finite Element Analysis for Dynamic Behavior of a Machine Tool Structure Fed in Open Loop Control," Transactions of the Korean Society of Machine Tool Engineers, Vol. 19, No. 5, pp. 596 602.

(2) Altintas, Y., 2000, Manufacturing Automation: Metal Cutting Mechanics, Machine Tool Vibrations, and CNC Design, Cambridge University Press, Cambridge, UK, pp. 65 228.

(3) Younkin, G. W., 1991, "Modeling Machine Tool Feed Servo Drives Using Simulation Techniques to Predict Performance," IEEE Transactions on Industry Applications, Vol. 27, No. 2, pp. 268 274.

(4) Choi, Y. H., and Hong, J. H., 2004, "A Study on the Feed Rate Optimization of a Ball Screw Drive System for Minimum Vibrations," Proceedings of Autumn Conf. of Korean Society for Noise and Vibration Engineering, pp. 962 966.

(5) Kim, S. H., Jung, J. H., and Kim, H. J., 2009, "Experiment Based Dynamic Analysis for High Accuracy Control of Feed System," Journal of the Korean Society of Marine Engineering, Vol. 33, No. 5, pp. 729 737.
(6) Vesely, J., 2009, “Complex Model of Machine Structure with Feed Drive," Int. J of Natural Sciences and Engineering, Vol. 2, No. 4, pp. 193 199.

(7) Kim, M. S., and Jung, S. J., 2003, "Integrated Design of High-speed Feed Drive Systems," Journal of the Korean Society of Mechanical Engineering, Vol. 27, No. 12, pp. 2028 2038.

(8) Lee, C. H., Ha, T. H., Lee, J. H., and Kim, Y. J., 2011, "Simulator of Accuracy Prediction for Developing Machine structures," Journal of the Korea Society for Precision Engineering, Vol. 28, No. 3, pp. 265 274.

(9) ADAMS, 2011, ANSYS User's Manual Version 2011, MSC. Software Inc.

(10) Norton, R. L., 2006, Machine Design: An Integrated Approach, 3rd ed., Prentice Hall, USA, Ch. 10.

(11) Cho, Y. D., Chung, W. J., Lee, C. M., and Yoon, S. H., 2008, "Study on Decreasing Displacement of the MC(machining center) Moved Column with High-speed for Optimization of Acceleration and DOE(Design Of Experiment)," Transactions of the Korean Society of Machine Tool Engineers, Vol. 17, No. 1, pp. 35 42.

(12) Kim, D. M., Kim, D. H., Park, K. K., and Choi, H. C., 2010, "Coupled Flexible Multi-body Dynamics and Controller Analysis of Machine tool," Transactions of the Korean Society of Machine Tool Engineers, Vol. 19, No. 3, pp. 307 312. 